\title{
Chemical Composition, Antibacterial and Antioxidant Properties of Essential Oil from the Rhizomes of Hedychium forrestii var. palaniense Sanoj and M. Sabu
}

\author{
SINJUMOL THOMAS* AND B. MANI ${ }^{1}$
}

Department of Botany, Vimala College, Thrissur-680 009, ${ }^{1}$ Postgraduate and Research Department of Botany, St. Thomas College, Palai, Arunapuram, Kottayam-686 574, India

Thomas and Mani: Composition, Antibacterial and Antioxidant Properties of Rhizome Oil of Hedychium forrestii

\begin{abstract}
The essential oil constituents of rhizomes of Hedychium forrestii var. palaniense were analyzed by gas chromatography and gas chromatography-mass spectrometry. A total of 26 constituents comprising $68.20 \%$ of the oils were identified. The volatile fraction was characterized by monoterpene hydrocarbons $(\mathbf{4 2 . 3 1 \% ) ,}$ oxygenated monoterpenes $(\mathbf{3 8 . 4 6} \%)$, sesquiterpene hydrocarbons $(\mathbf{1 5 . 3 8 \%})$ and oxygenated sesquiterpenes $(3.85 \%)$. The predominant constituents identified were $\beta$-pinene $(18.30 \%)$, $\beta$-linalool $(17.80 \%), 1,8$-cineole $(\mathbf{1 2 . 0 0 \%})$, and 4-terpineol $(\mathbf{5 . 5 0} \%)$. Sesquiterpenoids were present only in negligible quantities. The antibacterial activities of the essential oil was evaluated against ten bacteria and Pseudomonas aeruginosa was the most susceptible organism with a zone of inhibition of $42.16 \pm 0.76 \mathrm{~mm}$. Additionally, the essential oil showed promising radical scavenging and electron donating activity.
\end{abstract}

Key words: Hedychium forrestii var. palaniense, Zingiberaceae, $\beta$-pinene, $\beta$-linalool, 1,8-cineole, DPPH

The genus Hedychium J. Koenig comprises about 80 species, distributed from India to South East $\mathrm{Asia}^{[1]}$. This is considered to be the largest genus of Zingiberaceae in India with about 45 taxa $^{[2]}$. They are generally used as ornamentals and are also used for their industrial (paper manufacture and perfumery) or medicinal properties ${ }^{[3-5]}$.

Composition of essential oils from Hedychium species is characterized by the abundance of monoterpenes with major percentage of 1,8-cineole and pinene derivatives $^{[6]}$. Essential oils from $H$. spicatum, $H$. aurantiacum, $H$. coronarium and $H$. ellipticum exhibited good antioxidant potentials by quenching 1,1-diphenyl-2-picrylhydrazyl (DPPH) radicals and moderate to good $\mathrm{Fe}^{2+}$ chelating activity and could afford protection against oxidative damage ${ }^{[7]}$. Flower and leaf oils of $H$. gardnerianum showed good antimicrobial activity against Staphylococcus aureus and $S$. epidermidis ${ }^{[8]}$. The rhizome essential oil as well as solvent extracts of $H$. flavescens, $H$. venustum, $H$. ellipticum, $H$. aurantiacum and $H$. coronarium showed a broad antimicrobial spectrum ${ }^{[7,9-11]}$. Essential oil of $H$. spicatum is reported to possess antimicrobial and antioxidant activity ${ }^{[7,12]}$. Therefore, Hedychium species

*Address for correspondence E-mail: sunithatom@gmail.com

July-August 2016 not only have ornamental value but also have medicinal and industrial value.

Hedychium forrestii var. palaniense, a recently reported taxon, is known only from four localities of Pulney Hills, Tamil Nadu, at an altitude of 1300-1600 m. It prefers to grow in grassy slopes and open rock cliffs as patches of 15-20 mature individuals ${ }^{[13]}$. There are no previous reports of the essential oil composition and its biological properties of this new taxon. Therefore the present study aimed to analyze the essential oil composition, antibacterial and antioxidant potential of the essential oil isolated from rhizomes of this least studied taxon.

\section{MATERIALS AND METHODS}

The rhizomes of $H$. forrestii var. palaniense were collected from Perumalmalai $(1520 \mathrm{~m})$ region of Pulney Hills, Tamilnadu in the month of May, 2014.

This is an open access article distributed under terms of the Creative Commons Attribution-NonCommercial-ShareAlike 3.0 License, which allows other the remix, tweak, and build up to the non-commercially, as long as the author is credited and the new creations are licensed under the identical terms.

Accepted 03 July 2016

Revised 24 February 2016

Received 15 November 2015

Indian J Pharm Sci 2016;78(4):452-457 
Voucher specimen (RHT65200) has been deposited in The Rapinat Herbarium (RHT), St. Joseph's College, Tiruchirappalli, Tamilnadu.

\section{Chemicals:}

2,2-diphenyl-1-picrylhydrazyl (DPPH) and ascorbic acid (AA) were purchased from Sigma Chemical Co. (St. Louis, MO, USA). Potassium ferricyanide, trichloroacetic acid (TCA), and ferric chloride were purchased from Merck Chemical Supplies (Damstadt, Germany). All the chemicals used including the solvents, were of analytical grade.

\section{Essential oil extraction:}

Air dried rhizomes (25g) of the plant were hydrodistilled for $3 \mathrm{~h}$ using a Clevenger-type apparatus. The distilled oil was dried over anhydrous sodium sulfate, and stored in tightly closed vials at $4^{\circ}$ for analysis. The essential oil content was determined as percentage on dry weight basis as an average of three independent extractions.

\section{Characterization of essential oil:}

Gas chromatography-mass spectrometry (GC/MS) analysis was performed using Shimadzu GC-2010 gas chromatograph (GC-FID) equipped with QP 2010 mass spectrometer (MS). Approximately $0.1 \mu \mathrm{l}$ of pure oil sample was subjected to GC and GC/MS analysis. The column used was DB-5. The oven temperature was programmed as follows; $70^{\circ}$ for $5 \mathrm{~min}$ and then increased to $110^{\circ}$ at the rate of $5^{\circ} / \mathrm{min}$, then up to $200^{\circ}$ at the rate of $3 \% \mathrm{~min}$ and again up to $220^{\circ}$ at the rate of $5 \% \mathrm{~min}$, at which the column was maintained for 5 min; injector temperature of $250^{\circ}$. Helium was used as carrier gas at a flow rate of $1 \mathrm{ml} / \mathrm{min}$. Identification of the individual components was made by matching their recorded mass spectra and linear retention indices with the library (NIST and Wiley) provided by the instrument software, online database (http:// www.flavornet.org) and by comparing their calculated retention indices with literature value ${ }^{[14]}$.

\section{Test microorganisms:}

The bacterial strains used in the study were three Gram positive bacteria namely, Streptococcus haemolyticus (MTCC442), Bacillus cereus (MTCC430) and Staphylococcus aureus (MTCC87) and seven Gram negative, namely, Vibrio parahaemolyticus (MTCC451), Vibrio cholerae (MTCC3904), Salmonella paratyphi (MTCC735), Enterobacter aerogens (MTCC111), Escherichia coli (MTCC433), Klebsiella pneumoniae (MTCC3384), and
Pseudomonas aeruginosa (MTCC741). All the tested strains are reference strains, and were collected from Microbial Type Culture Collection (MTCC) and Gene Bank, Institute of Microbial Technology, Chandigarh, India.

\section{Antibacterial activity test:}

The antibacterial activity of essential oil was carried out by disc diffusion method ${ }^{[15]}$, recommended by Clinical and Laboratory Standards Institute (CLSI), using 25 $\mu \mathrm{l}$ of standardized suspension of test bacteria $\left(1.5 \times 10^{8}\right.$ $\mathrm{CFU} / \mathrm{ml}$ ) spread on Mueller-Hinton agar (MHA, $\mathrm{pH}$ $7.3 \pm 0.1)$ plates. The discs (6 $\mathrm{mm}$ in diameter) were impregnated with $20 \mu$ of essential oil, followed by air-drying and were placed on seeded agar plates. Amoxicillin $(30 \mu \mathrm{g} / \mathrm{disc})$ was used as positive control to determine the sensitivity of bacterial strain. The plates were incubated at $37^{\circ}$ for $24 \mathrm{~h}$. Antimicrobial activity was evaluated by measuring the zones of inhibition against the tested bacteria. Each assay was carried out in triplicate.

\section{DPPH radical scavenging assay:}

The free radical scavenging activity of essential oil was measured using the stable DPPH radical, according to the method of Blois ${ }^{[16]}$ with minor modification. Briefly, $0.1 \mathrm{mM}$ solution of DPPH in methanol was prepared and this solution $(1 \mathrm{ml})$ was added to essential oil in methanol $(3 \mathrm{ml})$ at concentrations ranging from 10-50 $\mu \mathrm{l} / \mathrm{ml}$. The mixture was shaken vigorously and left to stand for $30 \mathrm{~min}$ in the dark, and the absorbance was then measured at $517 \mathrm{~nm}$. The capability to scavenge the DPPH radical was calculated using the following equation: $\% \mathrm{DPPH}$ radical activity $=\left(\left(\mathrm{A}_{0}-\mathrm{A}_{1}\right) / \mathrm{A}_{0}\right) \times 100$, where $A_{0}$ and $A_{1}$ are absorbance of the control and of the sample, respectively. Ascorbic acid was used for comparison.

\section{Determination of reducing power:}

The reducing power of the essential oil was measured by making use of the method described by Yen and Duh ${ }^{[17]}$ with some modifications. Various concentrations (10, $20,30,40$ and $50 \mu 1 / \mathrm{ml}$ ) of essential oil in methanol was taken separately and mixed with $2.5 \mathrm{ml}$ of $0.2 \mathrm{M}$ sodium phosphate buffer ( $\mathrm{pH}$ 6.6). The dilute sample was then mixed with $5.0 \mathrm{ml}$ of $1 \%$ potassium ferricyanide and the mixture was incubated at $50^{\circ}$ for $20 \mathrm{~min} .5 .0 \mathrm{ml}$ of $10 \%$ trichloroacetic acid was added to the mixture and was centrifuged at $3000 \mathrm{rpm}$ for $10 \mathrm{~min} .5 .0 \mathrm{ml}$ of the supernatant solution was mixed with $5.0 \mathrm{ml}$ of distilled water and $1.0 \mathrm{ml}$ of ferric chloride (1\%). 
The absorbance was measured spectrophotometrically at $700 \mathrm{~nm}$ (Shimadzu, UV-150-02). Ascorbic acid standard was used for comparison.

\section{RESULTS AND DISCUSSION}

The dried rhizomes (25 g) were hydrodistilled to obtain a pleasant smelling, pale yellow colored oil at a yield of $1.2 \% \mathrm{v} / \mathrm{w}$. A GC of the volatile components of the rhizome is shown in fig. 1. The GC indicates the presence of more than 50 compounds, of which 26 were identified.

Table 1 lists the volatile components identified and those 26 constituents accounted for $68.20 \%$ of the oil hydrodistilled. The analyzed oil contained monoterpene hydrocarbons $(42.31 \%)$, oxygenated monoterpenes (38.46\%), sesquiterpene hydrocarbons (15.38\%) and oxygenated sesquiterpenes (3.85\%). The majority of the essential oil components were monoterpenes and the major constituents were $\beta$-pinene (18.30\%), $\beta$-linalool (17.80\%), 1,8-cineole (12.0\%), 4-terpineol $(5.50 \%), \quad \alpha$-pinene $(4.9 \%), \quad \gamma$-terpinene $(1.90 \%)$, borneol (1.60\%), $\alpha$-terpineol $(1.60 \%)$ and camphene $(1.40 \%)$. The sesquiterpene compounds were present in least concentration and germacrene B $(0.20 \%)$ was the leading one.

The present study showed that qualitative and quantitative differences were found among the oils of $H$. forrestii var. palaniense Sanoj and M Sabu and $H$. forrestii Diels which is a close relative of the taxon studied ${ }^{[18]}$. Sakhanokho et al. ${ }^{[18]}$ reported that the major components in the essential oil from dried rhizomes of $H$. forrestii were characterized by linalool (56\%), $\beta$-pinene (14\%) and 1,8-cineole (10.1\%) and found that the oil differs quantitatively from those of $H$. forrestii var. palaniense. It is interesting to see that, though the oils of both taxa contained monoterpenes $(87.5 \%$ in $H$. forrestii) and sesquiterpenes ( $8.33 \%$ in $H$. forrestii), hydrocarbon sesquiterpenes were not detected in $H$. forrestii. However, a diterpene was found in the rhizome essential oil of $H$. forrestii ${ }^{[18]}$.

Monoterpene constituents detected in the present study such as 4-thujanol, fenchol, p-menth-2-en-1ol, camphor, pinocarvone and bornyl acetate were absent in the earlier reports ${ }^{[18]}$. At the same time the monoterpenes detected in the essential oil of $H$. forrestii like, sabinene, myrcene, limonene, cymene, translinalool oxide and cis-linalool oxide were not found in the present study. Earlier reports also showed that major essential oil constituents are common among various species of Hedychium ${ }^{[9,18-21]}$ whereas minor components, which reveal the specific differences between taxa. Finally, we suggest that the differences in essential oil composition, both qualitative and quantitative, may depend on factors such as genotype, season and environment.

The results of the antibacterial studies of the essential oil obtained by the disc diffusion technique are given in Table 2. It was interesting to see that all the bacteria tested were susceptible and the essential oil showed hopeful antibacterial activity. A concentration of 20 $\mu 1$ of essential oil showed nearly equal and effective inhibition against all the strains used in the present study. The most susceptible bacterium tested was $P$. aeruginosa with a zone of inhibition of $42.16 \pm 0.76$ $\mathrm{mm}$. The results also showed that the essential oil was found to be more effective antibacterial agent than the standard antibiotic used in the study. Moreover, the

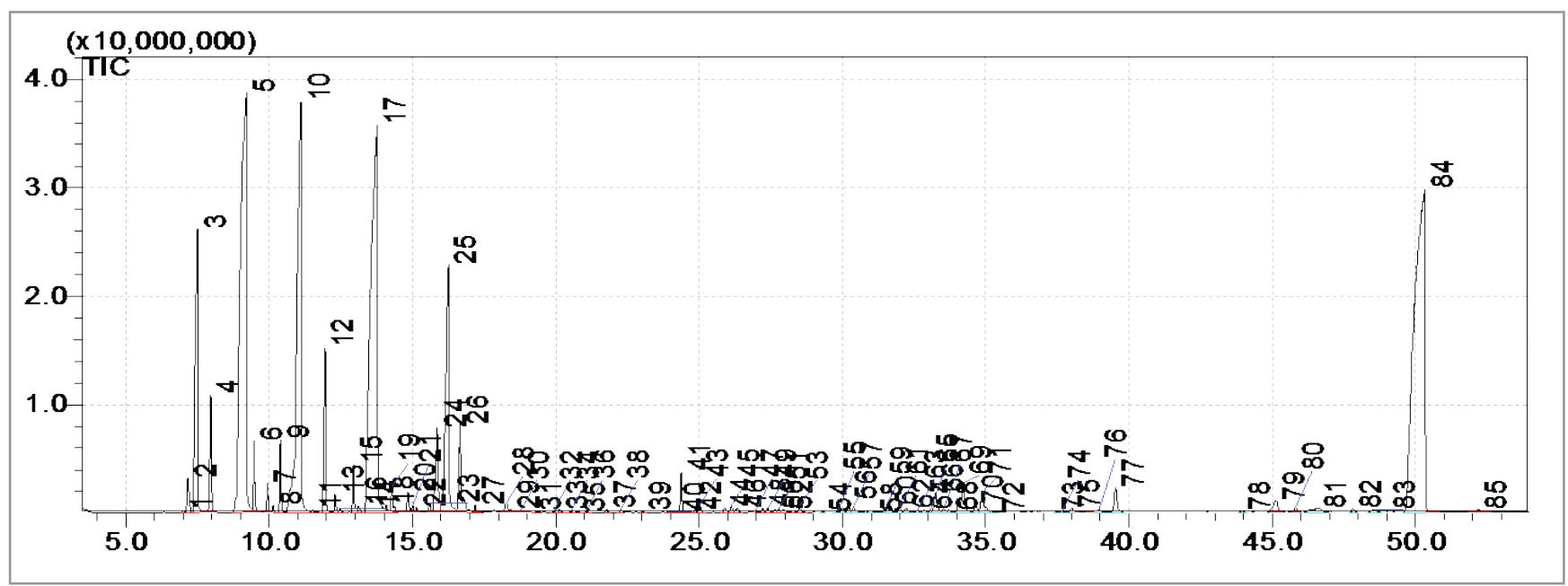

Fig. 1: GC-MS chromatogram of oil.

Total ion chromatogram (TIC) of the volatile compounds from dried rhizomes of Hedychium forrestii var. palaniense. 
TABLE 1: CHEMICALCOMPOSITION OF ESSENTIAL OIL EXTRACTED FROM DRIED RHIZOMES

\begin{tabular}{lccc}
\hline Component & $\mathbf{R I}_{\mathrm{a}}$ & $\mathbf{R I}_{\mathrm{b}}$ & Composition (\%) \\
\hline a-thujene & 936 & 938 & 0.5 \\
a-pinene & 938 & 939 & 4.9 \\
Camphene & 953 & 953 & 1.4 \\
B-pinene & 994 & 994 & 18.3 \\
a-phellandrene & 1007 & 1006 & 0.3 \\
3-careen & 1009 & 1009 & $\mathrm{tr}$ \\
a-terpinene & 1011 & 1012 & 0.8 \\
1,8-cineole & 1029 & 1030 & 12 \\
cis-B-ocimene & 1036 & 1038 & $\mathrm{tr}$ \\
4-thujanol & 1072 & 1073 & 0.2 \\
Y-terpinene & 1074 & 1074 & 1.9 \\
a-terpinolene & 1086 & 1086 & 0.5 \\
Linalool & 1098 & 1100 & 17.8 \\
Fenchol & 1139 & 1139 & $\mathrm{tr}$ \\
L-camphor & 1140 & 1139 & 0.3 \\
p-menth-2-en-1-ol & 1145 & 1145 & 0.1 \\
Pinocarvone & 1158 & 1160 & 0.1 \\
Borneol & 1163 & 1162 & 1.6 \\
4-terpineol & 1180 & 1179 & 5.5 \\
a-terpineol & 1192 & 1195 & 1.6 \\
Bornyl acetate & 1294 & 1287 & $\mathrm{tr}$ \\
d-elemene & 1338 & 1335 & $\mathrm{tr}$ \\
B-caryophyllene & 1466 & 1467 & 0.1 \\
B-sesquiphellandrene & 1558 & 1560 & 0.1 \\
Germacrene B & 1562 & 1562 & 0.2 \\
Caryophyllene oxide & 1574 & 1573 & $\mathrm{tr}$ \\
\hline
\end{tabular}

$\mathrm{RI}_{\mathrm{a}}$ and $\mathrm{RI}_{\mathrm{b}}$ : Experimental and reference retention indices; tr-trace $<0.1 \%$

TABLE 2: ANTIBACTERIAL ACTIVITY OF EXTRACTED ESSENTIAL OIL FROM RHIZOMES

\begin{tabular}{lcc}
\hline Species & Zone of inhibition (mm) \\
\cline { 2 - 3 } & Essential oil & Amoxicillin \\
\hline Vibrio parahaemolyticus $(-)$ & $36.33 \pm 0.57$ & $32.33 \pm 0.57$ \\
Bacillus cereus $(+)$ & $36.17 \pm 0.28$ & $34.00 \pm 0.50$ \\
Enterobacter aerogens $(-)$ & $34.20 \pm 0.23$ & $32.17 \pm 0.28$ \\
Salmonella paratyphi $(-)$ & $34.33 \pm 0.60$ & $32.67 \pm 0.57$ \\
Vibrio cholerae $(-)$ & $37.83 \pm 0.80$ & $36.33 \pm 0.60$ \\
Staphylococcus aureus $(+)$ & $37.83 \pm 0.76$ & $36.17 \pm 0.28$ \\
Escherichia coli $(-)$ & $36.00 \pm 0.86$ & $30.33 \pm 0.30$ \\
Streptococcus haemolyticus $(+)$ & $37.16 \pm 0.77$ & $34.16 \pm 0.29$ \\
Klebsiella pneumoniae $(-)$ & $38.20 \pm 0.28$ & $32.33 \pm 0.57$ \\
Pseudomonas aeruginosa $(-)$ & $42.16 \pm 0.76$ & $32.17 \pm 0.29$ \\
\hline
\end{tabular}

Values are presented as mean \pm SD of triplicate experiments; (+) Gram positive, (-) Gram negative

essential oil inhibit the growth of both Gram-positive and Gram-negative bacteria, consequently it may be used as a broad-spectrum natural antibacterial agent.

Monoterpenes are good antibacterial agents ${ }^{[22]}$ in particular the oxygenated compounds ${ }^{[23]}$. The major components in the essential oil of $H$. forrestii var. palaniense were $\beta$-pinene, linalool, 1,8-cineole and 4-terpineol, which were studied for their antibacterial properties previously. The earlier studies showed that $\beta$-pinene, linalool and 4-terpineol were found to be possess good antibacterial properties ${ }^{[22-24]}$ whereas 1,8-cineole was least effective ${ }^{[23,25]}$. However, recent studies showed that 1,8-cineole alone or in combination with other essential oils showed good antibacterial activity ${ }^{[10,26]}$ and this might be due to synergism ${ }^{[27]}$. Essential oil of $H$. forrestii var. palaniense showed a promising antibacterial activity and it might be attributed not only by the major constituents but also by the action of minor components. Hence, essential oil from rhizomes of this plant can be used in the antibacterial formulations, which in turn broadens its applications in the medicinal and industrial fields.

The antioxidant potential of the essential oil obtained from $H$. forrestii var. palaniense was studied by analyzing the radical scavenging capacity and electron donating ability of the constituents in the essential oil. The DPPH radical scavenging activities of the essential oil and standard antioxidative compound (ascorbic acid) are shown in fig. 2. The result showed a dose-dependent inhibition of DPPH radical by both oil and the standard and the scavenging capacity of the essential oil was significant when compared with that of standard. Concentration at which the oil decreased DPPH radical by $50 \%\left(\mathrm{IC}_{50}\right.$ values) was $34.0 \mu \mathrm{l} / \mathrm{ml}$. Correspondingly, $\mathrm{IC}_{50}$ value for ascorbic acid, used as standard, was $30.50 \mu \mathrm{g} / \mathrm{ml}$. The reducing power of a sample was related to its electron transfer ability and might, therefore, served as an indicator of its potential antioxidant activity. The reducing power of the essential oil and ascorbic acid increased with the concentration (fig. 3). The oil exhibited significantly higher activity than the standard ascorbic acid. The results of the present study suggest that essential oil isolated from $H$. forrestii var. palaniense has promising radical scavenging ability and potent reducing power. Antioxidant properties of essential oils such as lipid peroxidation, scavenging of free radicals, chelating metal ions, and reducing power are often come from their monoterpene hydrocarbons, oxygenated monoterpenes and sesquiterpenes ${ }^{[28,29]}$, which means that the strong antioxidant activity of essential oil from the rhizomes of $H$. forrestii var. palaniense may be related to the sum of the effects of constituents in the essential oil. Therefore, the high antioxidant activity of this essential oil strengthens their application for 


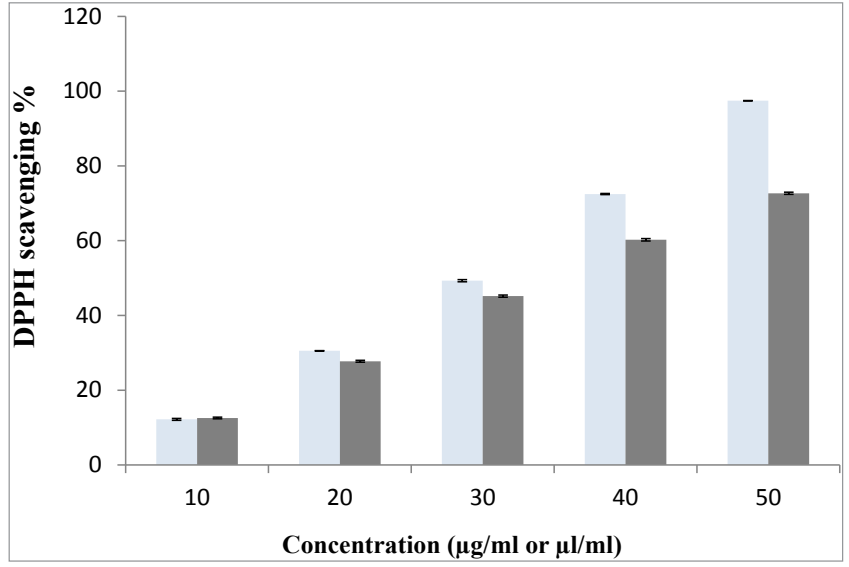

Fig. 2: DPPH radical scavenging activity.

DPPH radical scavenging activity of essential oil $(\mu \mathrm{l} / \mathrm{ml}, \sqcap)$ isolated from dried rhizomes of $\boldsymbol{H}$. forrestii var. palaniense and reference compound ascorbic acid $(\mu \mathrm{g} / \mathrm{ml},-)$. Values are mean \pm SD of triplicate experiments.

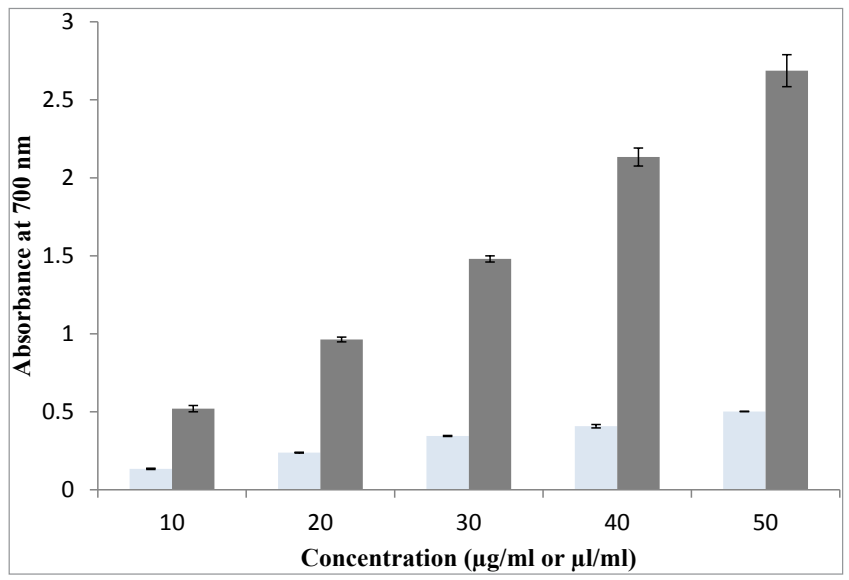

Fig. 3: Reducing power.

Reducing power of essential oil $(\mu \mathrm{l} / \mathrm{ml}$, -$)$ isolated from dried rhizomes of $\mathrm{H}$. forrestii var. palaniense and reference compound ascorbic acid $(\mu \mathrm{g} / \mathrm{ml},-)$. Values are mean \pm SD of triplicate experiments.

possible use as natural antioxidants.

\section{Financial support and sponsorship:}

Nil.

\section{Conflicts of interest:}

There are no conflicts of interest.

\section{REFERENCES}

1. Sirirugsa P, Larsen K. The genus Hedychium (Zingiberaceae) in Thailand. Nordic J Bot1995;15:301-4.

2. Thomas S, Mani B, Britto SJ. A new species of Hedychium (Zingiberaceae) from the southern Western Ghats, India. Webbia 2015;70:221-5.

3. He EY. Study on Hedychium coronarium Koenig's edibility and its pharmacological experiments. Lishizhen Medicine and Materia Medica Research 2000;11:1077-8.
4. Raj G, Dan M, Shiburaj S, Sethuraman MG, George V. Chemical composition and antibacterial activity of the rhizome oil of Hedychium larsenii. Acta Pharm 2005;55:315-20.

5. Gao L, Liu N, Huang B, Hu X. Phylogenetic analysis and genetic mapping of Chinese Hedychium using SRAP markers. Sci Hortic 2008;117:369-77.

6. Raj G, Dan M, George V, Sethuraman MG. Studies on chemical composition of essential oils from leaf and inflorescence of Hedychium larsenii M. Dan and Sathish. J Essent Oil Res 2013;25:33-8.

7. Joshi S, Chanotiya CS, Agarwal G, Prakash O, Pant AK, Mathela CS. Terpenoid compositions antioxidant and antimicrobial properties of the rhizome essential oils of different Hedychium species. Chem Biodivers 2008;5:299309.

8. Medeiros JR, Campos LB, Mendonca SC, Davin LB, Lewis NG. Composition and antimicrobial activity of the essential oils from invasive species of the Azores, Hedychium gardenarium and Pittosporum undulatum. Phytochemistry 2003;64:561-5.

9. Sabulal B, George V, Dan M, Pradeep NS. Chemical composition and antimicrobial activities of the essential oils from the rhizomes of four Hedychium species from South India. J Essent Oil Res 2007;19:93-7.

10. Joy B, Rajan A, Abraham E. Antimicrobial activity and chemical composition of essential oil from Hedychium coronarium. Phytother Res2007;21:439-43.

11. Thomas S, Britto SJ, Mathew S, Mani B. Evaluation of antibacterial potential of silver nanoparticles (SNPs) produced using rhizome extract of Hedychium coronarium J. Koenig. Int J Pharm Pharm Sci 2014;6:92-5.

12. Bisht GS, Awasthi AK, Dhole TN. Antimicrobial activity of Hedychium spicatum. Fitoterapia 2006;77:240-2.

13. Sanoj E, Sabu M, Kumar TR. Hedychium forrestii (Zingiberaceae) with a new synonymy and a variety from India. J Bot Res Inst Texas 2010;4:633-9.

14. Adams RP. Identification of essential oil components by gas chromatography/mass spectrometry. 4th ed. IL: Allured Business Media; 2009.

15. Bauer AW, Kibry WMM, Sherris JC, Turck M. Antibiotic susceptibility testing by a standardized single disc method. Am J Clin Pathol 1966;45:493-6.

16. Mani B, Thomas TD. Evaluation of the antioxidant potential of Pittosporum dasycaulon Miq. stem bark. Food Sci Biotechnol 2014;23:539-45.

17. Yen GG, Duh PD. Antioxidative properties of methanolic extracts from peanut hulls. J Am Oil Chem Soc 1993;70:383-6.

18. Sakhanokho HF, Sampson BJ, Tabanca N, WedgeDE, Demirci $\mathrm{B}$, Can Baser KH, et al. Chemical composition, antifungal and insecticidal activities of Hedychium essential oils. Molecules 2013;18:4308-27.

19. Weyerstahl P, Marschall H, Schneider S. Constituents of the essential oil from the rhizomes of Hedychium acuminatum Roscoe. Flavour Frag J 1995;10:179-85.

20. Weyerstahl P, Marschall H, Thefeld K, Subba GC. Constituents of the essential oil from the rhizomes of Hedychium gardnerianum Roscoe. Flavour Frag J 1998;13:377-88.

21. Verma RS, Padalia RC. Comparative essential oil composition of different vegetative parts of Hedychium spicatum Smith 
from Uttarakhand, India. Int J Green Pharm 2010;4:292-5.

22. Soković M, Glamočlija J, Marin PD, Brkić D, van Griensven LJLD. Antibacterial effects of the essential oils of commonly consumed medicinal herbs using an in vitro model. Molecules 2010;15:7532-46.

23. Kotan R, Kordali S, Cakir A. Screening of Antibacterial activities of twenty-one oxygenated monoterpenes. $\mathrm{Z}$ Naturforsch C 2007;62:507-13.

24. Park S, Lim YK, Freire MO, Cho E, Jin D, Kook J.Antimicrobial effect of linalool and $\alpha$-terpineol against periodontopathic and cariogenic bacteria. Anaerobe 2012;18:369-72.

25. Nakatsu T, Lupo AT, Chinn JW, Kang RKL. Biological activity of essential oils and their constituents. Studies Nat Prod Chem 2000;21:571-631.
26. Silvestre A, Cavaleiro J, Feio S, Roseiro J, Delmond B, Filliatre C. Synthesis of some new benzylic ethers from 1,8- cineole with antimicrobial activity. Monatsh Chem 1999;130:589-95.

27. Viljoen A, van Vuuren S, Ernst E, Klepser M, Demirci B, Baser H, et al. Osmitopsis asteriscoides (Asteraceae) - the antimicrobial activity and essential oil composition of a CapeDutch remedy. J Ethnopharmacol 2003;88:137-43.

28. Tepe B, Daferera D, Sokmen A, Sokmen M, Polissiou M. Antimicrobial and antioxidant activities of essential oil and various extracts of Salvia tomentosa Miller (Lamiaceae). Food Chem 2005;90:333-40.

29. Loizzo MR, Tundis R, Conforti F, Menichini F, Bonesi M, Nadjafi F, et al. Salvia leriifolia Benth (Lamiaceae) extract demonstrates in vitro antioxidant properties and cholinesterase inhibitory activity. Nutr Res 2010;30:823-30. 